\title{
Admirável mundo novo na perspectiva da tríade: Internet das Coisas, pessoas e mercados
}

José Edson Lara

http://orcid.org/0000-0001-6120-075X

\section{Luciano José Reis ${ }^{I I}$}

Thalles Augusto Tissot-Lara ${ }^{I I I}$

Altieres Oliveira SilvaIV

http://orcid.org/0000-0001-9940-6817

${ }^{I}$ Fundação Pedro Leopoldo, MG, Brasil.

PhD em Economia de Empresas - Universitat Autònoma de Barcelona.

Docente Mestrado Fundação Pedro Leopoldo.

${ }^{\text {II }}$ Fundação Pedro Leopoldo, MG, Brasil.

Mestre em Administração.

${ }^{\text {III }}$ Pontifícia Universidade Católica de Minas Gerais, MG, Brasil.

Graduado em Engenharia Mecânica.

${ }^{I V}$ Escola Superior de Propaganda e Marketing, SP, Brasil.

Mestre em Administração.

http://dx.doi.org/10.1590/1981-5344/3825

Este estudo aborda o tema Internet das Coisas (IOT) como inovação, impactando pessoas e mercados, a partir de novas formas de geração e de gestão de informações.Buscou-se caracterizar e desenvolver a IOT, e identificar as possíveis aplicações mais imediatas para o mercado e para a sociedade. Concretamente, estabelecese um mapa perceptual do estado das artes e das perspectivas da IOT como tecnologia, negócios e 
contribuições à melhoria da qualidade de vida de pessoas.Foi realizada uma pesquisa exploratória de caráter qualitativo, utilizando-se um guia de entrevista de profundidade sobre informações e percepções de um grupo de pessoas, referente à caracterização, estratégias de negócios, o consumidor e o futuro da Internet das Coisas. A coleta de dados foi realizada através de um formulário online e analisado por blocos de sub temas, utilizando o software VOSviwer para o estudo de recorrências de termos e/ou de palavras. Os resultados revelaram consonância entre o estudo, a proposição do mapa de gestão estratégico com foco em um ambiente de IOT e as respostas da pesquisa. Identificou-se que, mesmo sem possibilitar generalizações, as informações proporcionam uma demonstração sobre o estado atual da Internet das Coisas no Brasil e as relações de competitividade e estratégia das organizações.

Palavras-chave: Internet das Coisas; Tecnologia; Negócios; IoT; VOSviewer.

\section{Brave new world from the perspective of the triad: Internet of Things, people and markets}

This study approaches the Internet of Things (IOT) as innovation, impacting people and markets, from new forms of generation and information management. The aim was to characterize and develop the IOT, and to identify the most immediate possible applications for the market and for society. Specifically, a perceptual map of the state of the arts and the perspectives of IOT as technology, business and contributions to improving the quality of life of people is established. An exploratory qualitative research was conducted, using a depth interview guide on information and perceptions of a group of people, regarding the characterization, business strategies, the consumer and the future of the Internet of Things. The data collection was performed through an 
online form and analyzed by blocks of subthemes, using the VOSviwer software for the study of recurrences of terms and / or words. The results revealed consonance between the study, the proposition of the strategic management map with focus on an IOT environment and the research responses. It was identified that, even without generalizations, the information provides a demonstration about the current state of the Internet of Things in Brazil and the relations of competitiveness and strategy of the organizations.

Keywords: Internet of Things; Technology; Business; IOT; VOSviewer.

Recebido em 27.11.2018 Aceito em 01.06.2021 ${ }^{1}$

\section{Introdução}

A sociedade e o mercado têm demandado, em nossos tempos, um volume de interações e conexões substancialmente superior a pouco tempo atrás. Pela oferta, as empresas de base tecnológica estão gradualmente mais competitivas, provendo ao mercado, produtos e serviços cada vez mais sofisticados. Uma destas ofertas, que já se permite ser considerada uma revolução na inovação tecnológica e de interconectividade, é a chamada Internet das Coisas, ou Internet of Things (IoT). Esta tecnologia já estabelece conexões entre homens e máquinas, e máquinas com máquinas, proporcionando a formação de redes sociais e de mercado cada vez mais inteligentes. Este novo ambiente inteligente, em que os objetos se conectam formando uma grande rede de informações e possibilidades, segundo a literatura acadêmica e de negócios,é a primeira evolução real na internet, levando a um salto realmente significante nas aplicações sociais, com potencial de melhorar a forma como as pessoas vivem, trabalham, estudam e se divertem, conforme Hassan, Qamar, Hasan, Aman e Armed (2020), Yousif, Hewage e Nawaf (2021). Para Patel e Patel (2016), a Internet das Coisas refere-se à cada rede destinada a conectar qualquer coisa com a Internet, suportando-se em protocolos estipulados por equipamentos de identificação de informações para proporcionar intercâmbio de informações e comunicações, com o propósito de conquistar reconhecimentos, posicionamento, rastreamento, monitoramento e

\footnotetext{
${ }^{1}$ Artigo atualizado em maio de 2021.
} 
administração inteligentes. Neste contexto, a Internacional Telecomunication Union (ITU), conceitua IoT como uma infraestrutura global de informação para sociedade, com o avançado serviço de conectividade física ou virtual através da comunicação entre dispositivos (ITU, 2012).

Os estudos acadêmicos que abordam este tema têm surgido, preliminarmente, nas áreas de Engenharia e Ciência da Computação. Mezzanotte, Palazzie, Alimenti e Roselli (2021) demonstram que a ideia de IoT utilizando a RFID (identificador por rádio frequência) sugeriria que todos os objetos físicos poderiam ser conectados através da internet. Nas áreas de estratégia, Porter e Heppelmen (2014), Weintraub e Boreinstein (2017), Woetzel e Nyquist (2017), Fortino, Fotia, Messina, Rosaci e Sarné (2021) e muitos outros autores, vêm explorando o tema enquanto unidade analítica de estudos. Ainda se observa que grandes corporações como IBM, CISCO, Microsoft, Intel, Apple Inc. e organizações como ACATEC (National Academy of Science and Engineering, do Governo da Alemanha) e ITU (International Telecomunication Union),estão cada vez mais envolvidas nas múltiplas questões que abrangem a IoT. Estes estudos identificam que os avanços em RFID e sensor inteligente, conectividade sem fio e móvel, assim como a nanotecnologia, transformaria o desenvolvimento no mundo.

A IoT traz a proposta concernente a que os objetos estão e serão cada vez mais conectados entre si. Assim,forma-se uma estrutura global de objetos, chamados "inteligentes", que provém de uma interface em forma de serviços facilitados pela interação através da internet (YOUSIF; HEWAGE; NAWAF, 2021).A interação de máquina com máquina, que descreve a interconexão (geralmente sem fio) de dispositivos que anteriormente não se comunicavam, também conhecido pelo termo M2M (machine-to-machine), integrando as tecnologias 5G,proporcionará intensas conexões de dispositivos e gerando cerca de US\$100 Bilhões em 2028 (CASHMAN, 2021).

Inúmeros são os desafios constatados e percebidos para o empreendimento da IoT, a começar pela infraestrutura necessária para adotá-la, como, por exemplo, questões técnicas, confiabilidade, capacidade, energia, conectividade e capacitação de recursos humanos. Estudos e implementação de estratégias de atendimento pleno às demandas sociais e humanas são primordiais nos propósitos e processos de inserção e consolidação neste ambiente. No entanto, em TI (tecnologia da Informação), situações de armazenamentos de dados, tráfego de dados de borda, regras de abertura de dados, regulamentação, governança, interoperabilidade, privacidade e segurança, e requisitos de largura de banda deverão ganhar a importância necessária para se garantir o ambiente de IoT (SHAFIQUE; KHAWAJA; SABIR; QAZI; 
MUSTAQIM, 2017). A aplicação de Internet das Coisas ou (IoT) pode trazer avanços à forma de interação homem e homem $(\mathrm{H} 2 \mathrm{H})$, homem e máquina (H2M) e integração máquina com máquina (M2M). Segundo Ferrara, Mandal, Cortesi e Spoto (2020),os campos de aplicação de tecnologia da IoT são diversos e numerosos, crescendo virtualmente nas mais variadas áreas a cada dia.Áreas como a educação, esporte, indústria inteligente, cidades inteligentes, centros urbanos inteligentes, saúde,logística, telecomunicações e o setor de segurança entre outros, serão notadamente contempladas pelas possibilidades da IoT e novos negócios.

Este estudo tem como objetivo geral analisar o estado da tecnologia da Internet das Coisas, e como ela pode agregar benefícios sociais e competitividade nos negócios, conforme um painel de especialistas acadêmicos e profissionais. Os objetivos específicos consistem em: 1)Identificar a caracterização da IoT e sua tecnologia; 2) verificar a estrutura e os recursos ao seu empreendimento; 3)identificar as estratégias e aplicações de mercado da IoT; 4) buscar inferências e conjecturas sobre o envolvimento de usuários e consumidores; 5) identificar projeções para o futuro dos ambientes de IOT; e, 6) metodologicamente, apresentar os mapas perceptuais dos pesquisados, sobre o estado da arte e da perspectiva da IoT.

\section{Referencial Teórico}

Ao longo dos anos, notadamente nos países mais desenvolvidos, diversos mercados foram se tornando crescentemente mais disputados, em razão do surgimento de novos vetores de competitividade baseados em tecnologias. As empresas que atuam em cadeias de negócios e competem em segmentos suportados por tecnologias de domínio restrito, gradualmente foram se caracterizando como setores de alto potencial de crescimento rápido. Estes segmentos passaram a ser mais competitivos e a exercer elevado grau de complexidade técnico-gerencial, em função da pretendida garantia para sobrevivência e crescimento futuro. Estas empresas e corporações, assim como suas cadeias de negócios, passaram a ser consideradas como muito mais inteligentes do que outras atuantes em segmentos não tão desenvolvidos tecnologicamente. O próprio World Competitiveness Report (2020) estabelece a inteligência corporativa, ou negócios inteligentes, ou Strategic Intelligence, como parâmetro de competitividade de empresas e países. No contexto da tecnologia como estratégia das empresas,insere-se a "Internet of Things", ou Internet das Coisas, como elemento analítico de ambiente de negócios. Para Ferrara et al., (2020) e Porter e Heppelmann (2014)o termo IoT representa o crescimento do número de objetos inteligentes conectados e como este cenário oferece novas oportunidades. À medida em que se possui um 
ambiente vasto em poder de processamento e comunicação, dispositivos inteligentes e cada vez menores e a conectividade sem fio, devem expandir a forma de pensar a competitividade e estratégia das empresas.

Porter e Heppelmann (2014) e Grinin, Korotayev e Tausch (2016), apresentam as ondas da tecnologia de Informação (TI), emergindo entre 1960 e 1970, quando as atividades individuais passaram a ser automatizadas com processamento de pedidos, pagamento de contas, planejamento de recursos e manufatura,sempre auxiliados por computador, o que resultou no aumento de produtividade e na geração de uma infinidade de novas informações que poderiam ser processadas e analisadas em cada atividade, portanto influenciando na cadeia de valor. Em 1995 a internet começou a ser comercial com a entrada da Amazon e Echobay (Ebay), sendo que, logo após, em 1998, o Google foi incorporado à internet, conforme o Postscapes (2020). Porter e Heppelmann (2014) afirmam que as atividades foram integradas através do globo terrestre por canais; novos clientes externos foram alcançados pelas empresas, de forma a permitir às empresas, por exemplo, fecharem canais de distribuição internacionais,onde a cadeia de valor foi transformada, no entanto, sem afetar os produtos. Estes mesmos autores citam que esta terceira onda da Tecnologia da Informação, a IoT, se torna uma parte integrada dos produtos, com sensores integrados, processadores, softwares e produtos embarcados e conectados. Estes produtos com dados armazenados em nuvem (data cloud) sendo analisados, e executados através de alguma aplicação,proporcionam uma enorme quantidade de informações disponíveis e novas funcionalidades geradas para a sociedade a todo momento.

A IoT gera competitividade e impulsiona a estratégia das empresas e negócios. Segundo Attaran (2017) os executivos neste ambiente valorizam as oportunidades e tratam esta condição como emergencial para a IoT se fazer presente nas suas empresas, no nível de estratégia. Kahle, Marcon, Ghezzi e Frank (2020) constatam que produtos inteligentes conectados são o novo cenário de escolha de estratégia para definir como os valores serão criados e capturados pelas empresas. No nível operacional, Kahle, Marcon, Ghezzi e Frank (2020) e Attaran (2017)assegura que severos avanços necessitam ser realizados em hardwares e softwares, à medida em que desafios tecnológicos e mercadológicos vão emergindo, em razão da crescente competitividade, principalmente no desenvolvimento de produtos. Schwab e Davis (2018) referenciam a aplicação da Quarta Revolução Industrial, ou Industria 4.0,representando a maior oportunidade para se desenvolver a manufatura alinhada à produção inteligente, com potencial de alavancar o setor com soluções e serviços. Neste mesmo sentido estabelecem as contribuições da IOT no contexto das novas possibilidades tecnológicas, 
incluindo: Inteligência Artificial, Robótica, Impressão 3D, Engenharia Genética, Computação Quântica, Novos Materiais, Neurotecnologias, Biotecnologias, Inteligência Artificial (IA), Blockchain, Novas Tecnologias Computacionais, Realidade Virtual e Aumentada, além de outras tecnologias. Okolie, Kuyoro e Ohwo (2018) afirmam ainda que a evolução tecnológica de sistemas embarcados para Cyber-physical systems (CPS) ou sistema físico cibernético, que atua na comunicação avançada entre máquinas, representa o início da quarta revolução industrial a caminho da Internet das Coisas, com base de dados integrados e serviços, além de suprimir o paradigma da centralização para descentralização da produção industrial e de serviços.

A crescente literatura acadêmica, assim como a intensificação das aplicações corporativas sobre a IoT e suas aplicações, vem contribuindo à criação, sistematização e divulgação de muitas plataformas e arquiteturas demonstrativas dos ambientes e das estruturas internas destas tecnologias. Como exemplo, tem-se a taxonomia apresentada por Hassan et al.,(2020), que apresentam, além de uma arquitetura típica, uma taxonomia que engloba as aplicações em áreas como: industrial, comercial, infra-estrutura, ambiental, saúde e cidades inteligentes.

É de bom alvitre destacar as possibilidades de riscos que podem ser proporcionados pela implementação destas novas tecnologias, tais como a evidente redução de empregos, o aumento do distanciamento econômico e social de povos, a perda da privacidade individual, a concentração econômica em empresas e países mais poderosos,a extinção de significativo volume de empresas que não alcançam estas avanços técnicos, e o utilitarismo no uso do poder político, econômico e militar proporcionado pelos seus detentores, além de muitos outros (SCHWAB; DAVIS, 2018 e HARARI, 2017).

\subsection{A Internet das Coisas - IoT e os principais campos de aplicação}

A IoT requer uma infraestrutura que combine objetos inteligentes (wireless, sensores, robôs, etc..), rede tecnológica de sensores e seres humanos, utilizando diferentes protocolos de comunicação, porém interoperáveis, e realiza uma rede multimodal, heterogênica e dinâmica, que pode ser implantada em variados e diferentes espaços (plataformas de óleo, minas, túneis, florestas, etc..), ou em caso de emergências ou situação perigosa (áreas de radiação, fogo, terremotos, etc.) (ELADL, 2017). A IoT, pode ser definida em quatro estágios - Web 1.0, referindose à conexão e obtenção de informação na rede; em seguida Web 2.0, com a característica de conectar pessoas (Web Social); a Web 3.0, ou Web Semântica e a Web Ubíqua, que utiliza objetos inteligentes, com sensores inteligentes e multifuncionais (SHAFIQUE et al.,2017). Assim, a 
partir dos dispositivos ou objetos "Things" que dependem de suas capacidades funcionais (processamento computacional, rede de conectividade, energia) adaptando-se a situação e ao contexto (ambiente, tempo, espaço), podem ser ativados em diferentes formas e aplicados a cada necessidade. Algumas aplicações já identificadas são:em edifícios (comercial, institucional e industrial); em energia (oferta, demanda, alternativo, óleo/gás); em consumo doméstico (casa, infraestrutura, segurança, conveniências, entretenimento); em cuidados com saúde (medicina, assistência, in vivo, atendimento em casa, pesquisas); na industrial (produção, recursos e automação, processos, conversão, distribuição); em logística (veículos, não veicular, sistema de transporte); no varejo (especialidade, hospitalidade, Ioja, segurança, equipamentos, rastreamento); em infraestrutura pública (serviços de emergência, tecnologia da informação); em redes (pública e privada). A literatura, em decorrência dos avanços tecnológicos e das contribuições da Internet das Coisas à sociedade, aos negócios e às pessoas, vem apresentando significativa turbulência, Bonnet e Westerman, (2020), Langley et al., (2021), Okolie et al.,(2018), Billet (2015).

Conforme a fundamentação do estado da arte do tema, já apresentado neste tópico é possível expor o modelo analítico, que se constituiu no marco objetivo desta pesquisa.

\subsection{Modelo analítico da pesquisa}

Ainda que a literatura venha contemplando este complexo tema sob diversos matizes, é natural que muitos de seus aspectos ainda permaneçam obscuros, ou pouco claros, tanto no meio acadêmico, quanto na esfera das aplicações corporativas, e especialmente na consciência do público leigo. Assim, é possível inferir que conceitos, definições e taxonomias que tentam explicar nuances do tema não sejam de consciência clara para estes segmentos. Neste trabalho pretende-se desenvolver uma descrição do estado do tema, enfatizando fundamentos conceituais, suas finalidades e contribuições econômicas e sociais para pessoas, mercados e organizações. A premissa consiste em que a IoT pode figurar como tecnologia de processamento, sendo multiconectada e interagindo pessoas com o meio organizacional. Portanto,gera e transmite informações,provocando mudanças de modo incremental ou até mesmo disruptiva.

Conforme a fundamentação do estado da arte do tema, é possível expor o modelo analítico, que se constituiu como marco para esta pesquisa. 0 modelo elaborado e aplicado mescla a contextualização dos stakeholders da IOT, com os propósitos da pesquisa definidos em seus objetivos, conforme a Quadro 1. 
Quadro 1: Modelo analítico da pesquisa

\begin{tabular}{|c|c|c|}
\hline $\begin{array}{l}\text { Conceitos, } \\
\text { ambientes e } \\
\text { benefícios da } \\
\text { IOT }\end{array}$ & $>$ & $\begin{array}{l}\text { Para você, o que significa a Internet das Coisas? Você acredita que as pessoas, em geral, já } \\
\text { conhecem o que é a IoT? } \\
\text { Você conhece os ambientes da Internet das Coisas? Sabe sobre a abrangência seus } \\
\text { benefícios e riscos da loT? }\end{array}$ \\
\hline $\begin{array}{l}\text { Estrutura, } \\
\text { investimentos, } \\
\text { segurança e } \\
\text { posição sobre } \\
\text { IoT }\end{array}$ & $>$ & $\begin{array}{l}\text { Você conhece sobre a infra-estrutura estrutura necessária para a IoT? Qual é sua opinião } \\
\text { sobre os investimentos do Brasil, para a loT? } \\
\text { Qual é sua percepção sobre a segurança da informação na loT? Qual sua opinião sobre a } \\
\text { posição tecnológica do Brasil para a IoT? }\end{array}$ \\
\hline $\begin{array}{l}\text { Estratégia, } \\
\text { conhecimento } \\
\text { e cooperação } \\
\text { via IoT }\end{array}$ & 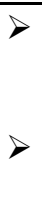 & $\begin{array}{l}\text { Para você, as organizações já vêem a loT como estratégia de negócios? Qual é a } \\
\text { emergência da adoção da loT pelo Brasil? } \\
\text { As organizações já compreendem a loT? Você sabe como a loT pode gerar cooperação } \\
\text { entre as pessoas, governos e mercado? }\end{array}$ \\
\hline $\begin{array}{l}\text { Aplicações, } \\
\text { negócios, e } \\
\text { evolução da } \\
\text { IoT }\end{array}$ & $>$ & $\begin{array}{l}\text { O que você pensa da tecnologia disponível no Brasil, para a loT? Você conhece as } \\
\text { aplicações mais imediatas da loT? Quais? } \\
\text { Como novos negócios podem ser compartilhados pela loT? Quais os setores no Brasil } \\
\text { estão mais desenvolvidos na implantação da loT? }\end{array}$ \\
\hline $\begin{array}{l}\text { Mudança e } \\
\text { controle } \\
\text { social pelo } \\
\text { IoT, geração } \\
\text { de produtos e } \\
\text { serviços }\end{array}$ & $>$ & $\begin{array}{l}\text { Você percebe a IoT como estratégia e estrutura de mudança social? Como? O que você } \\
\text { pensa sobre a loT como recurso de controle social? } \\
\text { Que pensa sobre a privacidade das pessoas em ambiente de loT? Os produtos se } \\
\text { adequarão mais aos consumidores, ou o contrário? } \\
\text { Pela loT, as pessoas irão influenciar direta mente na criação e desenvolvimento de novos } \\
\text { produtos e serviços? }\end{array}$ \\
\hline $\begin{array}{l}\text { Desafios, } \\
\text { profissões, } \\
\text { cidades } \\
\text { ambientes } \\
\text { futuros, com a } \\
\text { IoT }\end{array}$ & $>$ & $\begin{array}{l}\text { Quais são os principais desafios técnicos a serem enfrentados pelo Brasil, para a } \\
\text { intensificação da IoT? Como a loT pode influenciar os profissionais do futuro? Certas } \\
\text { profissões poderão ser suprimidas pela adoção da IoT? Que novas profissões surgirão? De } \\
\text { que forma? Como a IoT poderá tornar as cidades mais inteligentes e criativas? Quais as } \\
\text { principais precauções com a IoT? Como a combinação de ambientes inteligentes definirão } \\
\text { o cenário mundial? }\end{array}$ \\
\hline
\end{tabular}

Fonte: Modelo da pesquisa, 2021

A análise das funções, potenciais e atividades da IoT nas organizações será efetuada a partir da metodologia de estudo apresentada na próxima sessão.

\section{Procedimentos metodológicos}

Em razão do estado da arte do tema, esta pesquisa se fundamenta nos contextos epistêmicos, teóricos e morfológicos do conhecimento, caracterizando-se, portanto,como exploratória e qualitativa. $\mathrm{Na}$ abordagem epistêmica, o conhecimento ainda está em estágio emergente, sendo que as contribuições não estão suficientemente sistematizadas e 
organizadas, conforme os cânones de uma literatura robusta. No contexto teórico, o tema ainda está em fase de crescimento, embora acelerado, sendo que a literatura procede tanto de contribuições acadêmicas, quanto de organizações de produções tecnológicas e empresas de consultoria. No aspecto morfológico, este tema apresenta o potencial para a aplicação de múltiplas abordagens, tanto teóricas quanto metodológicas. Estas constituem razões fortes para as explorações deste promissor campo de conhecimentos e de atividades.

Neste estudo foi realizada uma pesquisa de profundidade, por meio de um guia de entrevistas, com um grupo de 16 profissionais de diferentes setores,procedentes do setor público, indústria, serviços e acadêmicos. No setor de serviços, entrevistou-se profissionais da área de saúde, de tecnologia da informação e ciências da computação.A seleção dos entrevistados ocorreu pelo critério de acesso ao tema, tanto na academia, quanto nas organizações. Foram identificados, preliminarmente, os profissionais que desempenham atividades nestas áreas,atuantes em fases de estudos e até de implementação embrionária de projetos de implantação de Internet das Coisas em processos tecnológicos e gerenciais. A maioria dos profissionais das organizações desenvolve conexões de conhecimento com outras instituições do exterior, sejam elas centros de ensino de alta performance ou empresas líderes em seus negócios.

A coleta dos conteúdos analíticos teve por propósito, além de caracterizar e descrever o tema, permitir o estabelecimento de hipóteses para estudos futuros, contribuindo ao avanço do conhecimento na área. 0 guia de pesquisa foi divido em blocos de perguntas sobre o tema sendo estes a caracterização e conceitos da IoT, estruturas e recursos necessários para um ambiente de IoT, a visão da IoT e a estratégia de negócios, as aplicações, o consumidor e a IoT, e o futuro da IoT. Foram realizadas perguntas com respostas abertas, no intuito de estimular os respondentes e escrever livremente sobre cada questão proposta. O guia foi enviado aos 16 respondentes por um link para acesso, o Google Forms. A pesquisa de campo foi realizada no período de 02/05/2021 e 31/05/2021.

Para a análise dos conteúdos, foi utilizado o software Vosviewer versão 1.6.5, para descrever o "texto geral" de cada bloco de perguntas. Este é um programa destinado a criar mapas a partir de base de dados, sendo seu principal uso a análise de redes bibliométricas. Também pode ser usado para explorar mapas com base em qualquer tipo de dados de rede. O objetivo da metodologia adotada foi gerar as unidades de significação de cada respondente, para possibilitar a procura por respostas e explicação para aquele universo estudado. A partir da análise de cada respondente, foi realizado um estudo interpretativo das respostas e 
realizada a comparação entre as respostas de cada um, com a finalidade de medir a densidade de recorrência dos termos e palavras que foram mais usadas por cada respondente e que foram coincidentes entre eles, reforçando assim a análise individual das questões.

\section{Apresentação e discussão de resultados sobre os conteúdos analíticos}

A característica da amostra, quanto à procedência institucional, foi: $43,8 \%$ da indústria e serviços, $31,3 \%$ do setor de tecnologia e inovação, $18,8 \%$ da academia e $6,3 \%$ do setor público e saúde.

\subsection{Caracterização do conhecimento e ambiente Internet das Coisas}

Considerando-se o conhecimento do tema e das implicações sociais como elementos essenciais, notadamente em profissionais e acadêmicos, buscou-se identificar o nível de conscientização dos respondentes sobre o cenário da IOT. Verificou-se a predominância dos respondentes (75\%) em associar a Internet das Coisas à inteligência dos equipamentos conectados à própria internet, à geração de informação e dados através de conexões, e a objetos sendo conectados a outros objetos através da internet para auxílio ao dia a dia das pessoas, das empresas e das organizações, assim como tratar de infraestrutura necessária como rede, wifi, de banda larga, e de informações em nuvem (armazenamento), podendo formar um ambiente em que os equipamentos físicos se comuniquem e gerem informações que possam ser utilizadas através da rede.

\subsection{Estruturas e recursos para atividade de IoT}

A estrutura e recursos necessários para a estratégia de IoT, ou para se formar um ambiente inteligente, decorre de uma adequada infraestrutura de rede de telecomunicações em sua origem, de dispositivos inteligentes com eficácia em trafegar dados, de competência em tratar dados, da capacidade em armazenar e proteger os dados, e da garantia da privacidade e segurança da informação. (81\%) dos respondentes citaram como ponto de impacto crítico a rede wifi ou rede sem fio, a demanda de melhorias necessárias de conexão de banda larga, além da capacidade de se armazenar dados em nuvens. A utilização de sistemas de transmissão de dados, o desafio da segurança e privacidade e a necessidade de políticas de incentivo do governo também foram citados. $(62,5 \%)$ respondentes acreditam que as perspectivas são de caráter tímido, devido a vários cenários, como a questão da política nacional. Há a sensação de que existe pouco esforço do setor público com o setor inovação, e que falta infraestrutura e investimentos nas áreas de tecnologia. Também se observa que existem iniciativas privadas nestas 
áreas, mas que não estão ainda alinhadas ao setor público. Buscou-se compreender ainda os desafios da segurança da informação, para os ambientes IoT. Os respondentes, em sua maioria, demostram preocupação com o tema da segurança da informação em ambientes inteligentes, com acesso e transmissão contínua de dados. Significativa maioria dos respondentes $(81,25 \%)$, disseram que o Brasil se encontra atrasado em pesquisa e investimento em tecnologia. Argumentam que existe um déficit de profissionais com conhecimento na área, que falta apoio do governo e do setor público e que o Brasil está tentando através das startups, se equalizar com grandes empresas alemãs do segmento em alguns setores.

O software VOSviewer permite demonstrar o resultado da aplicação dos referenciais semânticos, ou de cada palavra contida nas respostas dos entrevistados.Assim, para cada termo ou palavra adicionada, procedente das falas dos entrevistados sobre cada pergunta, a convergência dos significados ganha densidade, manifestando a cor vermelha. Com isto, caracteriza a respectiva zona de calor de cada termo. Significa que mais vezes houve recorrência desta palavra, e que por sua vez, foi alinhada a outras palavras e/ou expressões. O conjunto da palavra formado por "Brasil" foi o mais citado, com ocorrência das palavras "infraestrutura", "segurança", "IoT", "conexão", "desafio", "governo" e "sistemas". Depois aparece um segundo conjunto de palavras relacionadas a "estrutura", "setor", "pessoas" e "internet". Por fim um terceiro conjunto com "tecnologia", "wifi" e "grande desafio". A figura 1 traz um mapa de densidade de recorrência de palavras e termos identificados no texto dos respondentes do bloco de perguntas.

Figura 1 - Mapa de densidade de recorrência do texto dos respondentes sobre estrutura e recursos para uso da IoT elaborado pelos autores

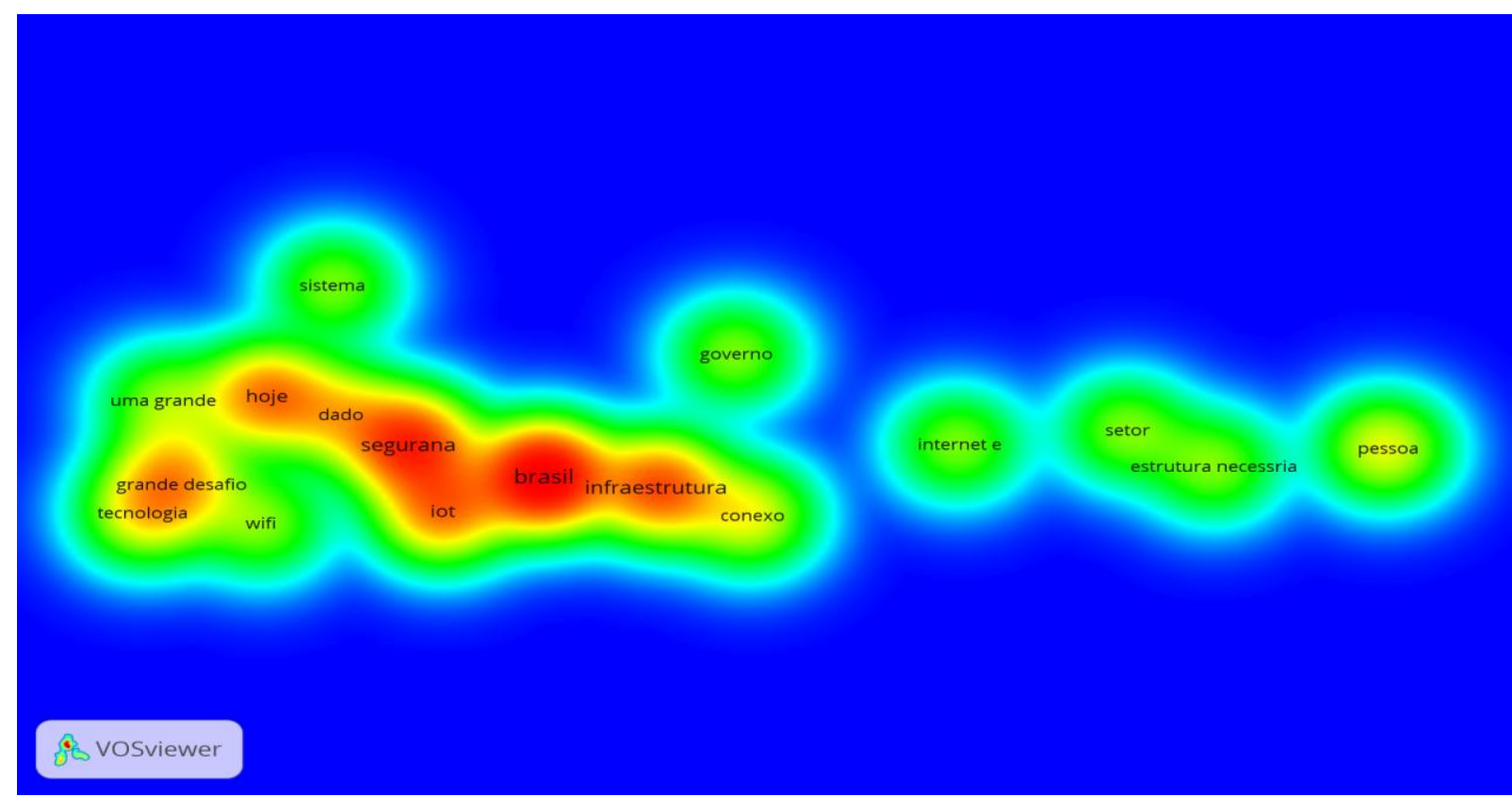


Fonte: informações da pesquisa, 2021

\subsection{Internet das Coisas como estratégia de negócios}

Este estudo buscou descrever a utilização da IoT como estratégia de negócios e como pode agregar valor na visão de negócios e nas necessidades dos consumidores. $43,75 \%$ dos respondentes visualizam a IoT claramente como estratégia de negócios, com características nas áreas comercias para a compreensão de demandas de clientes, gerando feedback através de informações coletadas de clientes para as organizações. A resposta mais contundente foi, "sim, pois é a fonte de feedback que as organizações possuem de mais relevante no momento", seguida da adoção de marketing devendo estar em harmonia com a informações de clientes geradas pela IoT. $50 \%$ dos respondentes conectaram suas respostas às questões relativas à geração de resultados, à redução de custos e à gestão de negócios facilitada pela adoção da IoT. Cerca de $25 \%$ entendem que existem situações mais urgentes em telecomunicações a serem abordadas, como banda larga, coberturas de wifi, e infraestrutura de rede de telecomunicações uma necessidade de preparo das pessoas, e funcionários das organizações para uso da IoT. Para 93,75\% dos respondentes, a interação entre usuários deve acontecer e é importante que aconteça com cooperação em projetos de inovação, na troca e compartilhamento de informações, nos ambientes de IoT. $\mathrm{Na}$ figura 3 é demonstrado o mapa de densidade de recorrência de palavras dos textos dos respondentes dentro da perspectiva do uso de IoT como elemento de estratégia de negócios. Assim, foram identificados os clusters de recorrências sendo um grupo relacionado a "adoção da tecnologia" com incidência ligada a custos, recursos envolvidos, benefícios. Um outro grupo de recorrência foi citado "tecnologia com aproximação a serviços" como forças deste cenário e ainda outros grupos em que é observado a relação com "vendas", "clientes e demandas", "usuário e consumo". Este mapa de calor busca de forma geral identificar as principais recorrências de palavras dentre as respostas sobre este tema. 
Figura 3 - Mapa de densidade de recorrência do texto dos respondentes sobre IoT como estratégia de negócios

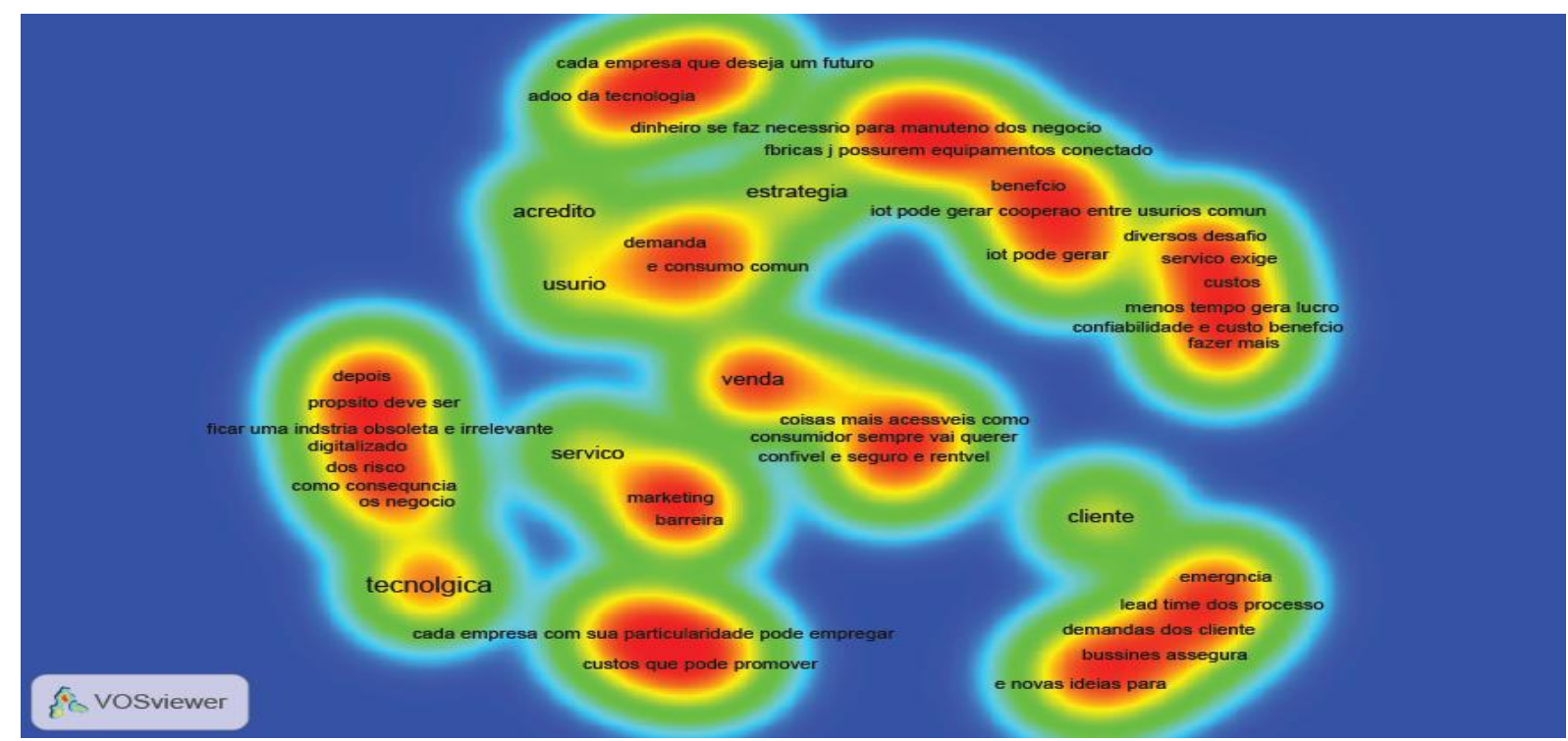

Fonte: informações da pesquisa, 2021

\subsection{Aplicações da IoT}

Almejou-se entender a percepção dos respondentes sobre a tecnologia e os dispositivos disponíveis encontrados no mercado. $56,25 \%$ dos respondentes disseram ser pouco acessível e limitada a disponibilidade desta tecnologia no mercado, justificando que muitos sensores, dispositivos, e tecnologia já estão disponíveis, mas ainda não estão sendo utilizadas pelas empresas. Sobre as aplicações mais imediatas para o uso da IoT para o mercado, 50\% dos respondentes opinaram como principais itens a área da saúde e hospitais, 31,2\% observaram sobre as indústrias (farmacêutica, mineração, automotiva, agricultura) e 25\% apontaram a importância do uso de IoT para a segurança pública e privada. A recorrência de termos e palavras nas respostas da pesquisa para esta questão é apresentada na figura 4. 
Figura 4 - Mapa de densidade de ocorrência do texto dos respondentes sobre áreas de aplicações de IoT mais imediatas para mercado

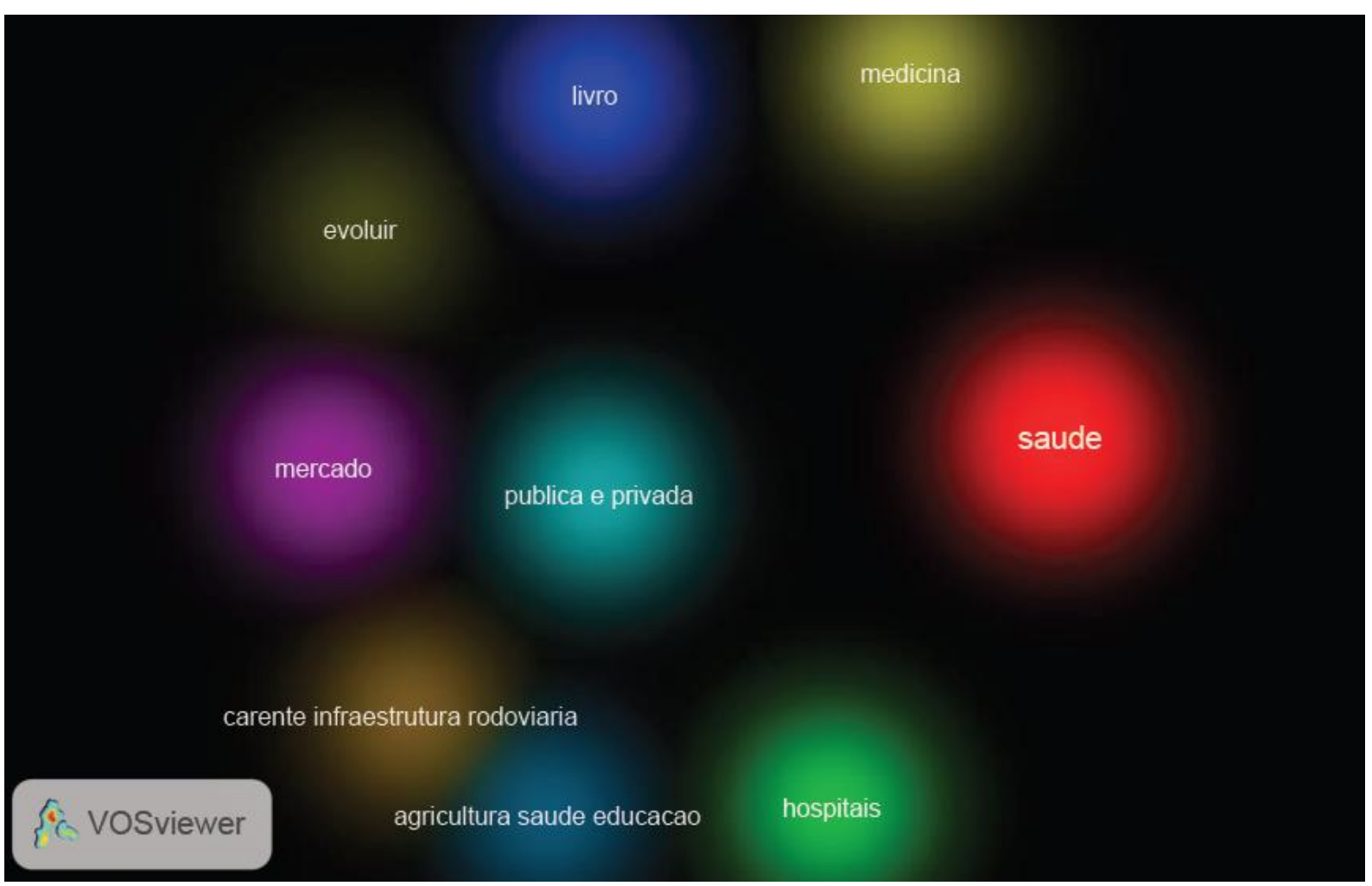

Fonte: informações de pesquisa, 2021

Sobre a utilização como objetos autônomos e seu uso, 37,5\% disseram que é necessário. No entanto necessitam ser monitorados por pessoas, e não devem suprimir vagas no mercado de trabalho. Cerca de $31,25 \%$ dos respondentes disseram que os objetos autônomos são o futuro desta tecnologia, sendo inevitável que aconteça de forma mais usual. As pessoas deverão se adaptar aos novos momentos que surgirão com o uso desta tecnologia. Todavia, cerca de $18,75 \%$ dos respondentes disseram não confiar e veem riscos para uso desta tecnologia. No contexto do compartilhamento de informação $31,25 \%$ não souberam responder esta questão sobre a analogia da aplicação da IoT com serviços e produtos compartilhados entre os fabricantes e prestadores de serviços. $18.75 \%$ disseram que as aplicações serão facilitadas pelas plataformas disponíveis às pessoas e outros 18,75\% apontam que a informação gerenciada por grupos de pessoas que de certa forma irão ditar as demandas futuras.

No que tange aos setores no Brasil que estão mais desenvolvidos em IoT, foi observado que 50\% apontaram a indústria, e 50\% destacam que esta não possui recursos para compra e uso desta tecnologia (!). Com a finalidade de caracterizar a recorrência dos termos e palavras dos textos dos respondentes sobre as questões das aplicações da IoT, suas 
características e setores foi realizado análise das 6 questões, conforme demostrado na figura 5 .

Figura 5 - Mapa de densidade de ocorrência do texto dos respondentes sobre áreas de aplicações de IoT

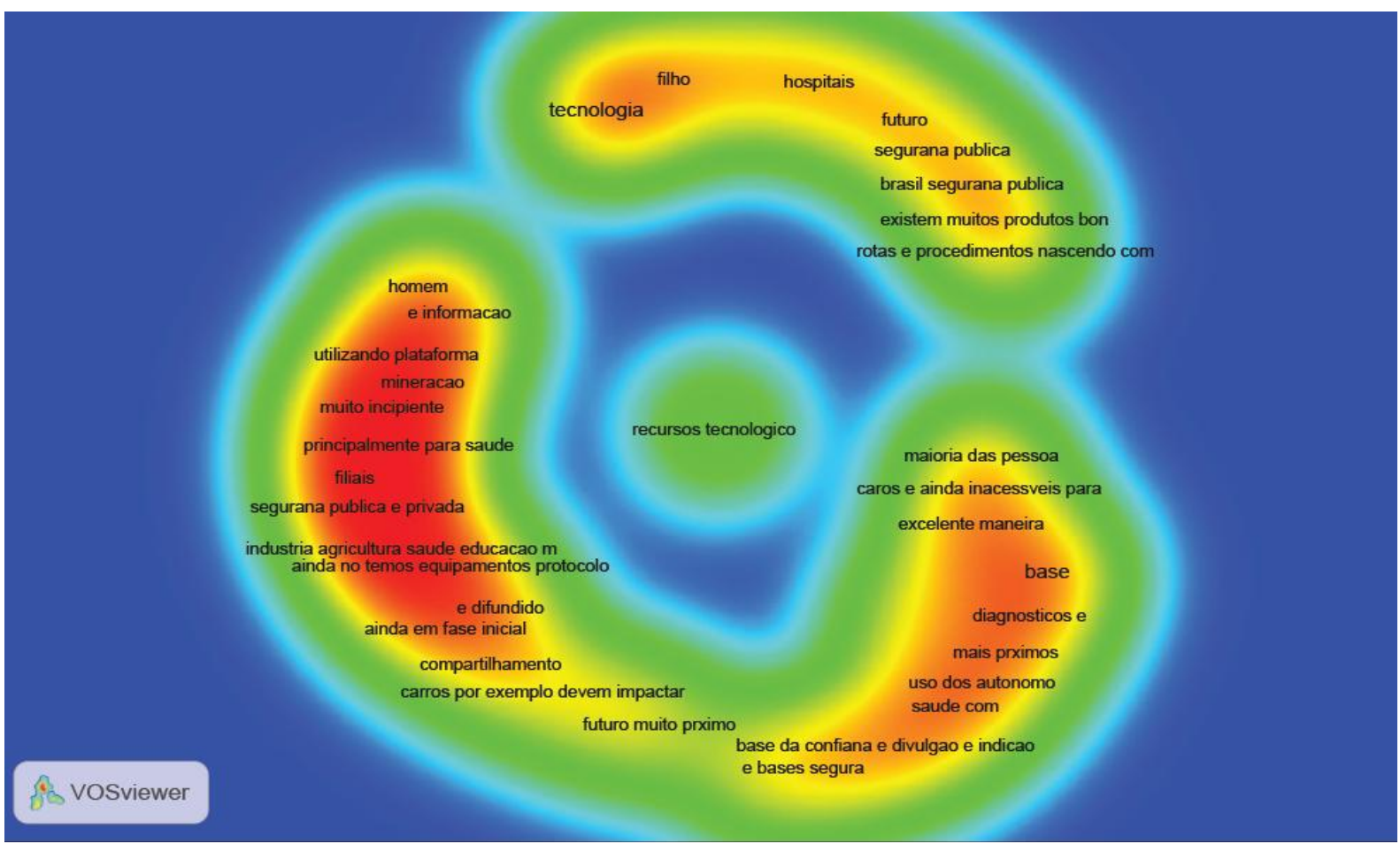

Fonte: informações da pesquisa, 2021

\subsection{O Consumidor e a IoT}

Sobre a percepção em relação aos consumidores de tecnologia de IoT no momento atual, seu uso social, ambiente necessário, questões relativas a privacidade e as possibilidades de abrangência social de seu uso, 50\% dos respondestes disseram que o uso da IoT influenciará os consumidores através da comunicação facilitada, causando impactos perceptíveis de mudança social, podendo ser também disruptiva em alguns aspectos, gerando mudança cultural. Na visão de outros $25 \%$ dos respondentes a relação com compartilhamento de informações, a formação de grupos, e as redes sociais podem resultar em ferramenta de mudança social em sua percepção. A Figura 6 demostra o mapa de recorrência de termos e palavras relativo à questão. 
Figura 6 - Mapa de densidade de recorrência sobre consumidor de IoT como estratégia de mudança social

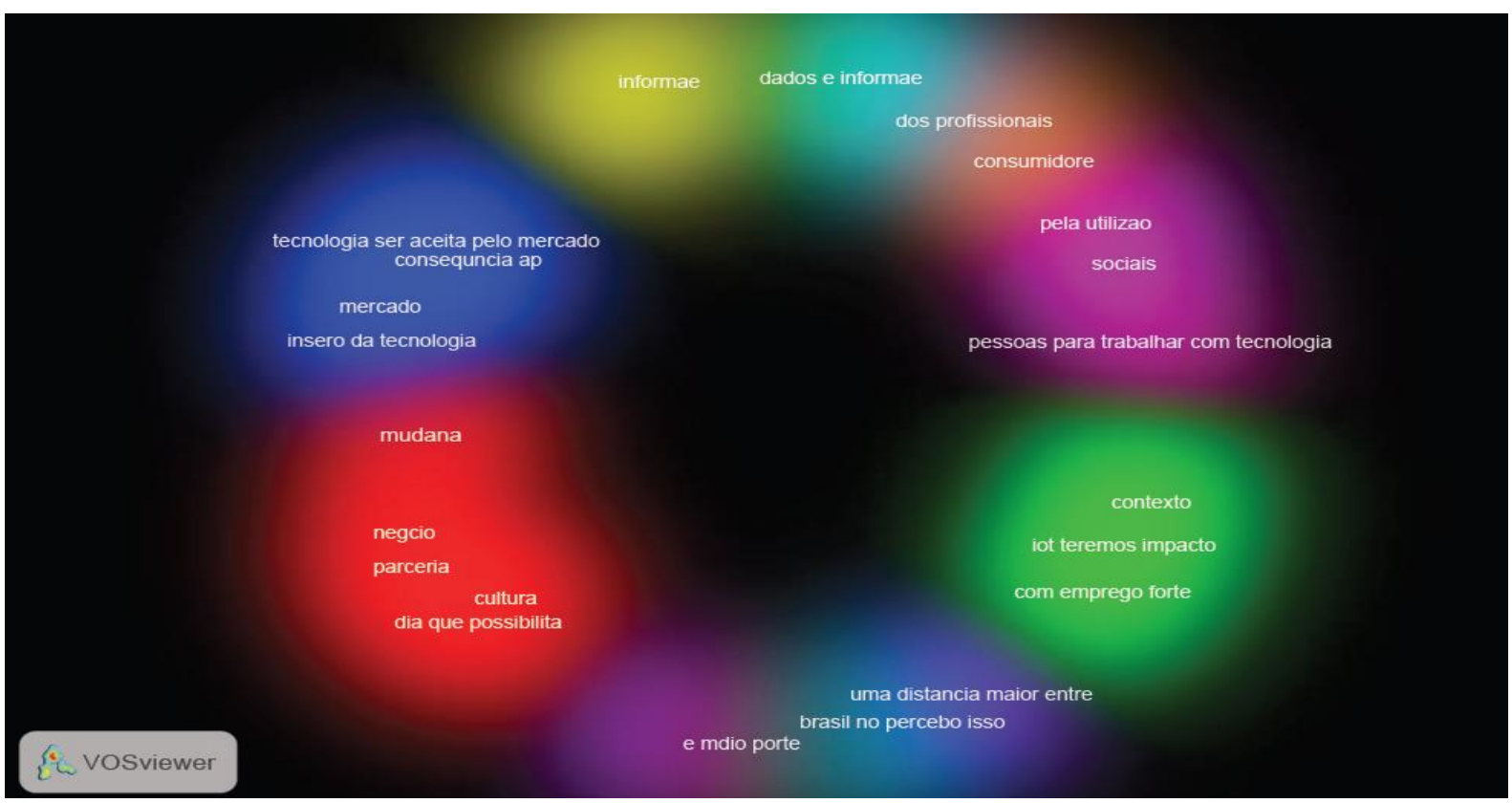

Fonte: informações da pesquisa, 2021.

Procurou-se compreender ainda a evolução da IoT enquanto ferramenta de controle e fiscalização social. Neste cenário, verificou-se que a maioria dos respondentes $(56,25 \%)$ disseram que entendem como alta, havendo uma facilidade de controlar, monitorar e fiscalizar as pessoas/sociedade a partir da evolução desta tecnologia, haja vista que haverá um fluxo de informações disponíveis no mercado, e que o crescimento e evolução desta tecnologia acarretará em uma necessidade de crescimento de segurança da informação e controle de privacidade. Sobre a identificação da percepção dos respondentes sobre os produtos, em seu início, se adequarão mais às necessidades de seus consumidores ou os consumidores se ajustarão aos produtos, constatou-se que $50 \%$ das respostas indicam que o produto deverá se adequar às necessidades dos clientes, em uma visão em que consumidor demanda um produto ou serviços e o mercado atende. Para 50\% dos pesquisados, a IOT implicará em significativas mudanças comportamentais, sendo que a interatividade homem-máquina e máquina-máquina levará a dependências atualmente imprecisas. $81,25 \%$ dos pesquisados, afirmam de forma contundente que as pessoas irão influenciar fortemente na criação de novos produtos e serviços através das facilidades criadas pela IoT, assim como esse campo de informações do cotidiano dos consumidores, deve gerar novas oportunidades e possibilidades de criação de produtos e serviços.

Em relação às questões sobre o consumidor de IoT, sua percepção sobre o uso da tecnologia e as possíveis transformações sociais que podem ter advindo deste cenário, a figura 7 demonstra que as respostas 
se dispõem bem definidas em grupos relacionados a citações de recorrências dos termos e palavras deste tema.

Figura 7 - Mapa de densidade de recorrência sobre o consumidor de IoT

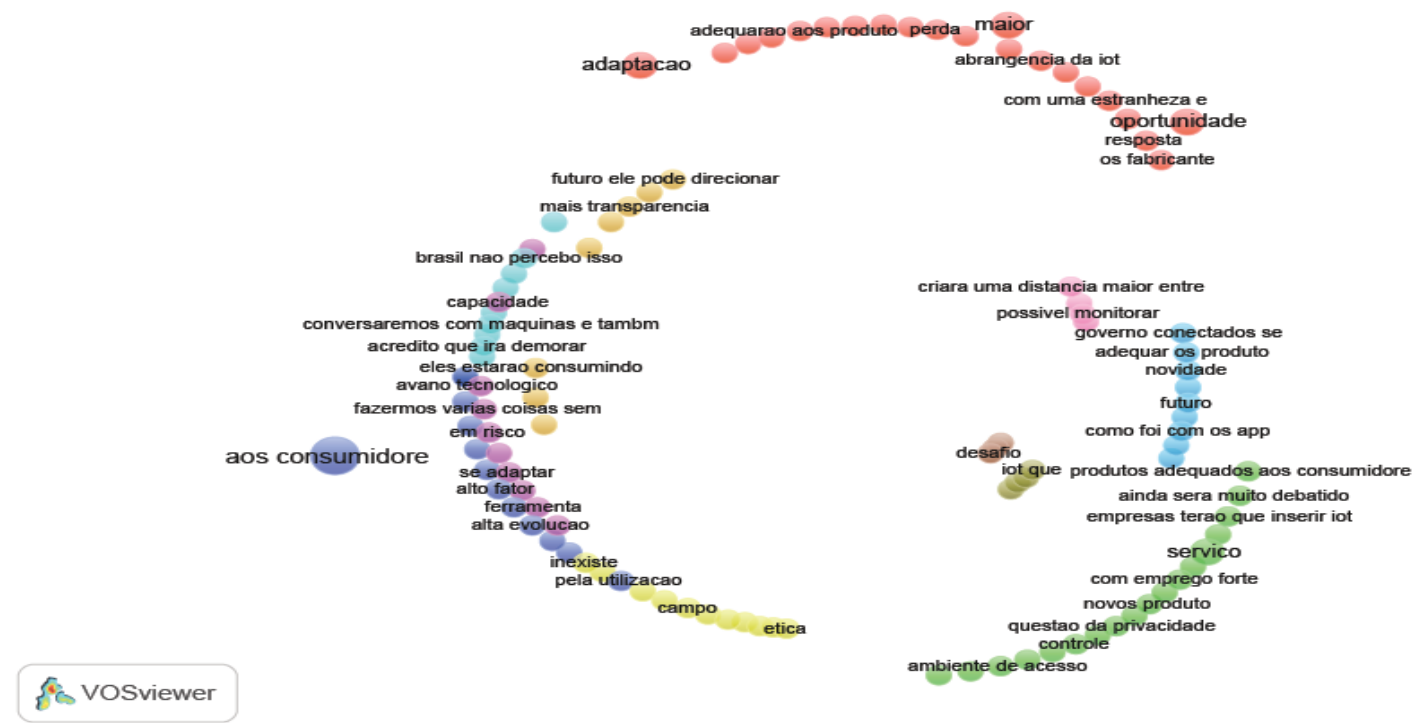

Fonte: Informações da pesquisa, 2021.

\subsection{Sobre o Futuro da IoT}

Neste contexto, buscou-se identificar os principais desafios técnicos a serem abordados no Brasil, em relação ao uso da tecnologia IoT. Observou-se um substantivo volume de argumentos sobre as necessidades para o avanço futuro da tecnologia. Portanto, as questões de infraestrutura de rede de telecomunicações e wifi foram fortemente mencionadas $(75 \%)$, seguida da tecnologia de segurança de dados e informações e da qualificação de profissionais como sendo necessários para o futuro da tecnologia IoT. Similarmente, foram mencionados a questão das políticas necessárias e apoio do governo para desenvolvimento da IoT no país, a questão do custo benefício da tecnologia e a dificuldade de se encontrar matéria prima para aplicação da tecnologia, uma vez que vários sensores e dispositivos são importados. Sobre a possibilidade da IoT influenciar os profissionais do futuro, $56,25 \%$ analisam como uma necessidade a evolução da educação para gerar conhecimento tecnológico, com uma nova visão de ensino, o qual deverá preparar as pessoas para novas demandas de mercado. Foi observado por $37,5 \%$ que, com a automação e os objetos autônomos principalmente na indústria, várias profissões serão suprimidas, pois as rotinas serão realizadas por máquinas e equipamentos, e frequentemente sem a presença do homem, enquanto que $37,5 \%$ dos respondentes atestam que novas profissões surgirão sem necessariamente suprimir outas. 
Em relação ao tema das cidades inteligentes e como estas podem trazer benéficos à sociedade, os respondentes citaram a qualidade de vida e a sustentabilidade como benefício imediato à população, seguido da melhoria da saúde e da segurança pública e privada $93,7 \%$ e $87,5 \%$. As atividades de pesquisas, logística, trânsito, compartilhamento de informações e controle do comportamento humano nas cidades foram observados por $75 \%$. No que tange às principais preocupações com o uso da IoT, constatou-se que $43,75 \%$ dos respondentes entendem que a principal preocupação é com a segurança da informação e a privacidade, para se garantir o uso correto da tecnologia.

Relativamente aos ambientes inteligentes, robótica, IoT e indústria 4.0, podendo definir o novo cenário de tecnológico mundial, os respondentes entenderam que a evolução desta tecnologia deve melhorar a vida das pessoas de forma impactante. Com o uso intenso de equipamentos automatizados e acompanhamento de um movimento orgânico de crescimento das sociedades urbanas, a competitividade corporativa deve crescer. Os mercados são turbulentos e rápidos em produção, acesso e cópias de tecnologias.

Com o propósito de se elaborar uma análise do resumo deste construto foram agrupados todos os textos das perguntas em conjunto, para tratar a densidade das recorrências de palavras e termos relativos ao futuro da IoT. Nota-se que quanto mais citadas os termos ou palavras, mais elas se aproximam da cor vermelha, porém com um menor o número de citações, elas se aproximam da cor verde, como pode ser observado na figura 8.

Figura 8 - Mapa de densidade de recorrência sobre o futuro de IoT

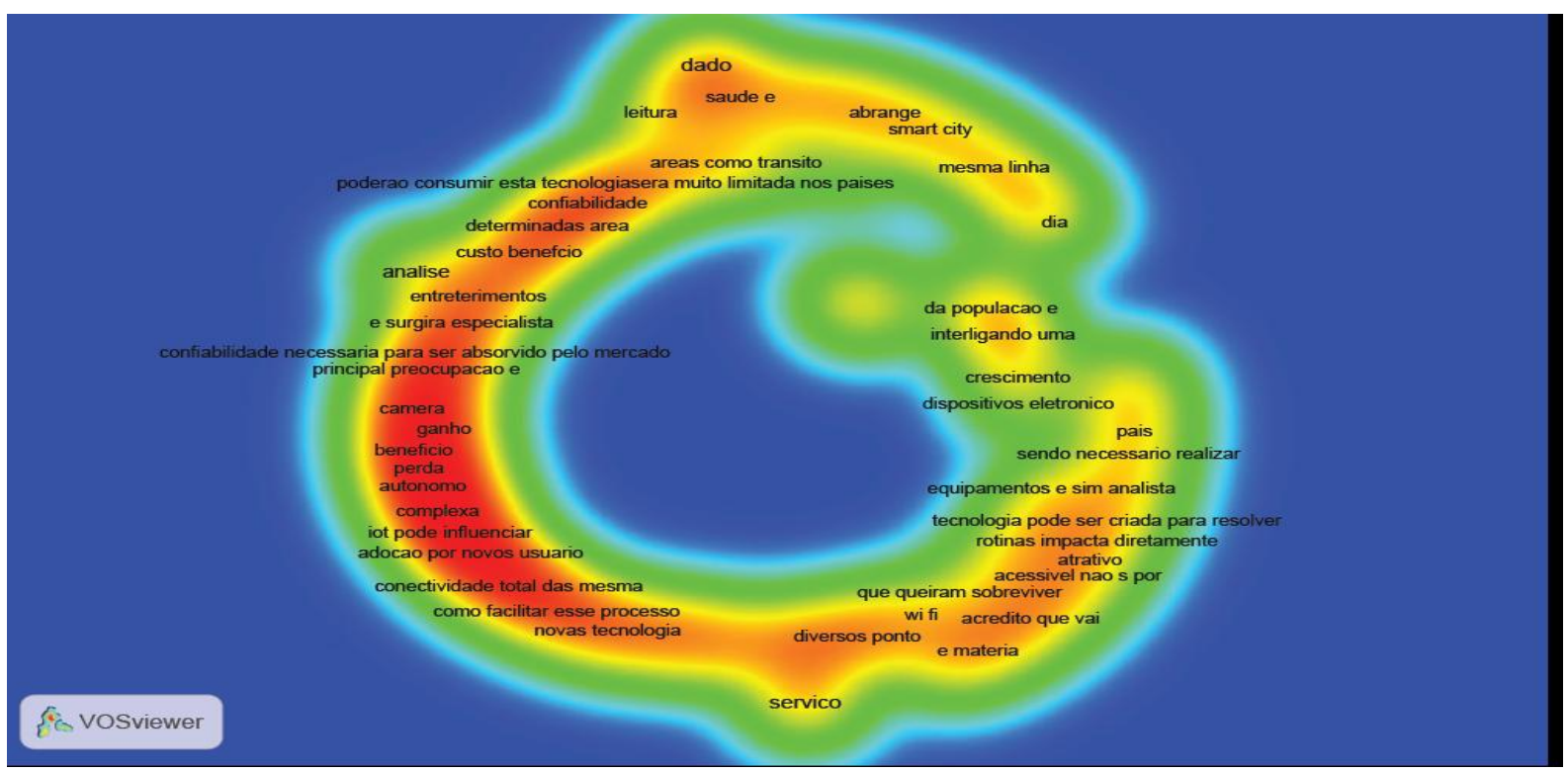

Fonte: Informações da pesquisa, 2021. 


\section{Considerações Finais \\ 5.1 Resumo e conclusões do estudo}

Em consonância com os propósitos e processos de um trabalho científico, a fundamentação desta pesquisa consistiu em verificar, essencialmente, se os objetivos do estudo foram atendidos e em que nível. O primeiro objetivo específico deste estudo buscou as percepções sobre a caracterização da IoT e sua tecnologia. Constatou-se que a percepção dos respondentes da pesquisa sobre o conceito e caracterização da tecnologia se alinha, em $62,5 \%$ das respostas, aos conceitos apresentados na literatura, notadamente Lopes e Moori (2021) no estudo sobre a mediação entre gestão estratégica de logística e a performance operacional. Eles não se mostram muito otimistas com os investimentos em infraestrutura de rede telecomunicações no Brasil e sobre a segurança da informação observando que questões como legislação e defesa do consumidor devem ser aprimoradas. Portanto, conclui-se que esta caracterização representa uma contribuição deste objetivo para a exploração em estudos futuros.

O segundo objetivo específico consistiu em verificar a estrutura e os recursos ao seu empreendimento. Constatou-se que muitos dos elementos estruturais são ainda inexistentes ou precários, notadamente no Brasil. Entretanto, o mercado encontrará soluções, facilitando as ações corporativas e sociais. Este resultado não encontra consonância absoluta com o estudo de Cavalieri (2021), sobretudo quanto á constatação daquele autor sobre a interoperabilidade suportada na definição de uma ontologia comum, que é um requisito muito forte no campo da rede elétrica inteligente. O Brasil ainda necessita se desenvolver neste quesito, o que demonstra dificuldade, face às dimensões físicas deste país. Quanto ao terceiro objetivo específico, identificando as aplicações e estratégias de mercado de IoT, 56,25\% disseram que esta tecnologia é pouco acessível e disponível no mercado, exceto para dispositivos embarcados em novos veículos. Quando se trata de aplicações mais imediatas para o mercado, os respondentes priorizaram as áreas de saúde e os hospitais, seguidas por setor farmacêutico, a mineração, o setor automotivo, a agricultura, a segurança pública e privada. Este objetivo encontra ressonância parcial ao trabalho desenvolvido por Singh, Agrawal, Sahu e Kazancoglu (2021). Esses autores encontraram significativa consistência em se explorar as oportunidades, desafios e resultados da incorporação da análise de big data (BDA) no setor de saúde. Neste estudo, estes resultados não foram expressados pelos entrevistados. O quarto objetivo buscou descrever as percepções sobre o futuro da IOT, permitindo-se concluir que as escolhas corporativas estratégicas, as decisões de abertura ou aplicações de mercado apoiadas por informações provenientes da IoT e a definição de 
métodos e estratégias com base em informações diretas dos consumidores para apoiar na tomada de decisão estratégica, haverão de ser elementos essenciais no futuro. Estas percepções encontram ressonância parcial em relação ao estudo realizado na Europa, por Alshammari, Beach e Rezgui (2021), sobre o futuro da IoT, notadamente como uma tecnologia ainda em construção, para utilização intensa em diversos ambientes e sistemas. O quinto objetivo foi o estabelecimento dos mapas de percepções conceituais da perspectiva da IoT pelas unidades de observação. Eles estão explícitos nas diversas figuras. Atualmente significativo número de pesquisadores em diversas partes do mundo estão se utilizando do Vosviewer e de outras plataformas para se processar pesquisas qualitativas, visando melhor configuração tecnológica e, portanto, mais inteligente, para se obter informações mais detalhadas em suas investigações científicas. Este estudo se utilizou desta tecnologia, à exemplo de outras pesquisas de profundidade, tal como o fizeram, por exemplo, Guleria e Kaur (2021) e Lara et al., (2019), propondo hipóteses para estudos bibliométricos.

Foi possível explicar os objetivos específicos e apresentar a relação do referencial teórico com a análise de resultados desta pesquisa. Nesta perspectiva, os resultados deste estudo contribuem para a análise do estado atual da tecnologia, originando uma projeção de como a Internet das Coisas pode agregar valor aos negócios e à vida de pessoas. Este estudo oferece um olhar reflexivo sobre a Internet das Coisas, alinhandose ao momento atual das tecnologias em evolução disponíveis no mercado, além de buscar uma visão metodológica inovadora neste processo de estudo. Compreende-se que, apesar das informações não permitirem uma generalização sobre o estado das artes do tema, oferecem uma perspectiva de uma amostra de profissionais sobre 0 momento atual da IoT no Brasil.

\subsection{Proposições para novos estudos}

Em razão do estado incipiente do tema em estudo, a Internet das Coisas, bem como da escassa concepção sobre todos os seus matizes conceituais, taxonômicos e nomológicos, elaborou-se uma pesquisa de natureza qualitativa, buscando percepções de escopo generalista em relação a elementos básicos da realidade executiva do assunto. Neste contexto, propõe-se novas investigações que permitam criar, constatar e validar hipóteses tais como:

H1: Existe, entre profissionais e acadêmicos, uma convergência de percepções sobre a Internet das Coisas;

H2: O Brasil já possui infraestrutura suficiente para começar a aplicar a Internet das Coisas; 
H3: O Brasil já possui condições para o oferecimento de segurança da informação, no contexto da Internet das Coisas;

H4: As organizações já estão se preparando para adoção das estratégias e estrutura requeridas pela Internet das Coisas;

H5: Os consumidores já estão aptos à adoção de práticas proporcionadas pela Internet das Coisas;

H6: As organizações estão propensas à formação de recursos humanos requeridos pela adoção da Internet das Coisas;

H7: A adoção da Internet das Coisas permitirá o desenvolvimento imediato de novos produtos e serviços;

H8: Os acadêmicos estão otimistas sobre a Internet das Coisas, como elementos de criação de melhor qualidade de vida as pessoas;

H9: Os executivos organizacionais estão otimistas sobre a Internet das Coisas, como elementos de criação de melhor qualidade de vida as pessoas;

H10: A Internet das Coisas proporcionará economias de energia;

H11: A Internet das Coisas criará melhores condições para sustentabilidade ambiental;

H12: O tema "Internet das Coisas" será, brevemente, intensamente explorado em pesquisa acadêmicas e tecnológicas.

Estas são algumas hipóteses que se propõe para novos estudos no futuro, a serem explorados por programas de investigação científica e tecnológica, notadamente empreendidas em universidades, centros de pesquisa corporativos e pesquisadores independentes.

\section{Referências}

ALSHAMMARI, K.; BEACH, T.; e REZGUI, Y. Cybersecurity for digital twins in the built environment: current research and future directions. Journal of Information Technology in Construction (ITcon), v. 26, p. 159-173, 2021. Disponível em: DOI: 10.36680/j.itcon.2021.010. Acesso em: 30 maio 2021.

ATTARAN, M. The internet of things: limitless opportunities for business and Society. Journal of Strategic Innovation and Sustainability , v. 12, n.1, 2017. Disponível em:

https://www.researchgate.net/publication/314089633 The Internet of $\mathrm{T}$ hings Limitless Opportunities for Business and Society/link/5980d552a 6fdccb310ff1785/download. Acesso em: 30 mar. 2021.

BILLET, B. Système de gestion de flux pour l'internet des objects intelligents. (Tese de Doutorado em Informática e sistemas distributivos). 
Université de Versailles Saint-Quentin-En-Yvelines, FR, França). 2015.

Disponível em: https://tel.archives-ouvertes.fr/tel-01166047/document. Acesso em: jun. 2020.

BOGERS, M.; BURCHARTH, A.; CHESBROUGH, H. Open Innovation in Brazil: Exploring Opportunities and Challenges. International Journal of Professional Business Review, São Paulo (SP), v. 6, n. 1, p. e213, 2021. DOI: $10.26668 /$ businessreview/2021.v6i1.213. Disponível em: https://www.openaccessojs.com/JBReview/article/view/213. Acesso em: 21 jun. 2021.

CAVALIERI, S. Semantic Interoperability between IEC 61850 and oneM2M for IoT-Enabled Smart Grids. Sensors, v. 21, 2021. Disponível em: https://www.mdpi.com/1424-8220/21/7/2571. Acesso em: 01mai. 2021

CASHMAN, G. On the Edge of Glory: Enabling a New Internet Machine Age. MC Partners. 12/Mai/2021. Disponível em: https://www.rtinsights.com/on-the-edge-of-glory-enabling-a-newinternet-machine-age/. Acesso em: 01jun. 2021

CHAN H. C. Y. Internet of things business model. Journal of service science and management, 2015. Disponível em:

https://www.researchgate.net/publication/282528695 Internet of Things Business Models. Acesso em: 12 jun. 2020.

CISCO. The digitization of the healthcare industry. Using technology to transform care. Cisco International Business Solution Group. 2016.

Disponível em: https://blogs.cisco.com/healthcare/the-digitization-of-thehealthcare-industry. Acesso em: 09 jun. 2020.

CISCO, I.T.U. Harnessing the internet of things for global development. A contribution to the broadband commission for sustainable development. 2016. Cisco-ITU. Disponível em: https://halberdbastion.com/technology/iot/harnessing-internet-thingsglobal-development. Acesso em: 26 mar. 2020.

CRUZARA, G.; SANDRI, E. C.; CHEROBIM, A. P. M.; FREGA, J. R. The value at the industry 4.0 and the digital transformation process: evidence from Brazilian small enterprises. Revista Gestão \& Tecnologia. v. 21, n.1, p. 117-141. 2021. Disponível em:

http://revistagt.fpl.edu.br/get/artide/view/1860. Acesso em: 20 jun.2021

DAVIS, M. Semantic wave 2008 report: industry roadmap to web 3.0 \& multibillion dollar Market opportunities. 2008. Disponível em:

http://www.eurolibnet.eu/files/REPOSITORY/20090507165103 Semantic WaveReport2008.pdf. Acesso em: 25 jun. 2020. 
DHL Trend Research, CISCO (2015). Internet of Things in logistics. A collaborative report by DHL and CISCO on implications and cases for the logistic industry. DHL-CISCO. Disponível em:

http://www.dhl.com/content/dam/Local_Images/g0/New aboutus/innovat ion/DHLTrendReport Internet of things.pdf. Acesso em: 29 jul. 2020;

ECK, N. J.; WALTMAN, L. O. Manual do VOSviewer version 1.6.4. Universiteit Leiden. Disponível em:

https://www.vosviewer.com/documentation/Manual VOSviewer 1.6.4.pdf Acesso em: 6 abr. 2020.

ELADL, G. H. Technical Requirements for the Application of Internet of Things. International. Journal of Computer Science and Network, v. 6, n. 4, Ago. 2017. Disponível em:

https://www.researchgate.net/profile/Gamal-Awad-

Eladl/publication/324538559 Technical Requirements for the Applicatio $\underline{\mathrm{n}}$ of Internet. Acesso em: 18 mar. 2021.

FERRARA, P.; MANDAL, A. K.; CORTEZI, A. ; SPOTO, F. Static Analysis for discovering IOT vulnerabilities. International. Journal on Software Tools for Technology Transfer. V. 23, p.71-88. 2021. Disponível em: https://link.springer.com/article/10.1007/s10009-020-00592-x. Acesso em: 22 abr. 2021

FORTINO, G.; FOTIA,L.; MESSINA, F.; ROSACI, D.; SARNÉ, G. M. A blockchain-based group formation strategy for optimizing the social reputation capital of an IoT scenario, Simulation Modelling Practice and Theory. v. 108, abr. 2021. Disponível em: https://www.sciencedirect.com/science/artide/abs/pii/S1569190X203018 91. Acesso em:22 abr. 2021.

GALEGALE, G.; SIQUEIRA, E. ; SILVA, C.B.H.; SOUZA, C.A. Internet das coisas aplicadas a negócio: um estudo bibliográfico. Revista de Gestão e Tecnologia e Sistemas de Informação. v. 13, n. 3, p. 423-438. 2017. Disponível em:

https://www.google.com/search?q=GALEGALE $\% 2 C+$ G. $\% 3 B+$ SIQUEIRA $\%$ 2C+E. \%3B+SILVA\%2C+C.B.H. \%3B+SOUZA\%2C+C.A. +Internet+das +coi sas. Acesso em: 18mar. 2021

GULERIA, D.; KAUR, G. Bibliometric analysis of ecopreneurship using VOSviewer and RStudio Bibliometrix, 1989-2019, Library Hi Tech, v. ahead-of-print No. ahead-of-print. Disponível em: https://doi.org/10.1108/LHT-09-2020-0218. Acesso em: 31 maio 2021.

IERC Internet of Things. Strategic research roadmap. IERC. Disponível em: http://www.internet-of-things-research.eu. Acesso em: 12 mar. 2020. 
GRININ, L; KOROTAYEV, A; TAUSCH, A. Kondratieff Waves and Technological Revolutions, Economic Cycles, Crises, and the Global Periphery. 2016. Disponível em:

https://www.researchgate.net/publication/309448110 Kondratieff Waves and Technological Revolutions. Acesso em: 22 abr. 2021.

GTA Germani Trade and Investments. 2014. Disponível em: https://www.gtai.de/GTAI/Navigation/EN/Invest/Industries/Industrie-40/Why-germany/industrie-4-0-why-germany-policy, $t=$ the-new-hightechstrategy,did=1798578.html. Acesso em: 20 ago. 2020

HARARI, Y. N. Homo Deus: uma breve história do amanhã. São Paulo. Cia. das Letras. 448 p. ISBN: 978-9588931623

HASSAN, R.; QAMAR, F.; HASAN, M. K.; AMAN, A. H. M. ; AHMED, A. S. Internet of Things and Its Applications: A Comprehensive Survey. Symmetry, v.12, p. 2-29. 2020. Disponível em: https://www.mdpi.com/2073-8994/12/10/1674. Acesso em: 26 maio 2021

KAHLE, J.H.; MARCON, E.; GHEZZI, A.; FRANK, A.G. Smart Products value creation in SMEs innovation ecosystems. Technological Forecasting and Social Change, 156, p. 1-38. Disponível em: https://www.researchgate.net/publication/340657579 Smart Products v alue creation in SMEs innovation ecosystems. Acesso em: 21 abr. 2021

LANGLEY, D. J. ; DOORN, J. V.; NG, I. C. L. ; STIEGLITZ, S. ; LAZOVIK, A. ; BOONSTRA, A. The Internet of Everything: Smart things and their impact on business models. Journal of Business Research, v. 122, p.853-863, jan. 2021. Disponível em:

https://www.sciencedirect.com/science/article/pii/S014829631930801X. Acesso em: 14 mar.2021.

LARA, J. E. ; LOCATELLI, R. L. ; RAMALHO, W. ; TISSOT-LARA, T. A. Bahia, E. T. Hedonic and utilitarian motivations: a study applied to wine consumption. cyrus Chronicle Journal, v.1, n.1, p. 39-50. 2019. Disponivel em: https://cyrusik.org/ccj/files/2021/04/Hedonic-and-UtilitarianMotivations-A-Study-Applied-to-Wine-Consumption-1.pdf. Acesso: em 4 mar. 2021.

LOPES, Y. M.; MOORI, R. G. The role of IoT on the relationship between strategic logistics management and operational performance. Revista de Administração Mackenzie, v.22, n.3, p. 1-27, 2021. Disponível em: https://www.scielo.br/j/ram/a/ngpXgK3x4p 7GqhRWPwnDV9k/abstract/?la ng=pt. Acesso em: 22 maio 2021. 
MASCENA, K. M. C.. ;SANTOS, F. V.;STOCKER, F. Priorização de Stakeholders em Gestão de Projetos: Aplicação do Método de Análise de Hierarquia Multicritério - AHP. International Journal of Professional Business Review, v. 6, n. 1, e195.Disponivel em: https://doi.org/10.26668/businessreview/2021.v6i1.195. Acesso em: 20 jun. 2021.

MEZZANOTTE, P.; PALAZZI, V.; ALIMENTI, F; ROSELLI, L. Innovative RFID Sensors for Internet of Things Applications. IEEE Journal of Microwaves, vol. 1, no. 1, p. 55-65. 2021. Disponível em: https://ieeexplore.iee.org/document/9318750. Acesso em: 22 fev. 2021.

MRUGALSKA, B.; WYRWICKA, M.K. Towards lean production in industry 4.0. 7th Conference on Engineering, Project, and Production Management. ScienceDirect, 2017. Disponível em:

https://www.sciencedirect.com/science/article/pii/S1877705817312717. . Acesso em: 24 jun. 2020.

NAGAOKA, H.; NAKAMURA, T.; NAKAGAWA, T.; KANEDA, M.Development of methods for visualising custumers value in terms of people and management. 2016. Hitachi Review, Disponível em: http://www.hitachi.com/rev/pdf/2016/r2016 02 104.pdf. Acesso em: 12 jun. 2020.

OKOLIE S.O.; KUYORO S.O.: OHWO O. B. Emerging Cyber-Physical Systems: An Overview. International Journal of Scientific Research in Computer Science, Engineering and Information Technologym, v. 3, n.8, 306-316. Disponível em: https://www.researchgate. net/publication/329819974 Emerging CyberPhysical Systems An Overview. Acesso em: 29 mar. 2021

PATEL, K.K; PATEL, S. M. Internet of Things-IOT: Definition, Characteristics, Architecture, Enabling Technologies, Application \& Future Challenges. International Journal of Engineering Science and Computing, v.6, n.5. Disponível em:

https://www.researchgate.net/publication/330425585 Internet of Things z

IOT Definition Characteristics Architecture Enabling Technologies Applic ation Future Challenges. Acesso em: 20 maio 2020

PORTER, M. E.; HEPPELMAN, J. E. How smart connected products are transforming competition. Harvard Business Review, 2014. Disponível em: www.hbr.org/2014/11/how-smart-connected-products-are-transformingcompetition. Acesso em: 20 maio 2020. 
POSTSCAPES. Want more free IoT industry info? Postscapes. 2017. Disponível em: https://www.postscapes.com/iot-history/. Acesso em: 25 nov. 2020.

SCHWAB, K; DAVIS, N. Aplicando a Quarta Revolução Industrial. São Paulo. Edipro, 2018.

SHAFIQUE, K.; KHAWAJA, B. A.; SABIR, F; SAMEER QAZI, S.; MUSTAQIM. Internet of Things (IOT) For Next-Generation Smart Systems: A Review of Current Challenges, Future Trends and Prospects for Emerging 5G-IoT. Scenarios. IEEE Access. V.20, p.1-21, 2017. Disponível em: https://ieeexplore.ieee.org/document/8972389. Acesso em: 01 fev. 2021

SINGH, R.K. ; AGRAWAL, S.; SAHU, A. ; KAZANCOGLU, Y. Strategic issues of big data analytics applications for managing health-care sector: a systematic literature review and future research agenda. The TQM Journal, v. ahead-of-print, n. ahead-of-print. Disponível em: https://www.emerald.com/insight/content/doi/10.1108/TQM-02-20210051/full/html. Acesso em: 14 maio 2021.

YOUSIF, M.; HEWAGE, C.; NAWAF, L. IoT Technologies during and Beyond COVID-19: A Comprehensive Review. Future Internet, v. 13, n. 105, 2021. Disponível em: https://doi.org/10.3390/fi13050105. Acesso em: 02 mar. 2021.

ZANELLA, A. ; BUI, N. ; CASTELANNI, A. ; VANGELISTA, L.; ZORZI, M. Internet of things for smarts cities. Internet of Things Journal, 2014. Disponível em: http://ieeexplore. ieee.org/stamp/stamp.jsp?arnumber $=6740844$. Acesso em 05 ago. 2020.

WOETZEL, J.; NYQUIST, S. How the natural resources business is turning into a technology industry. Harvard Business Review, 2017. Disponível em: https://hbr.org/2017/06/how-the-natural-resources-business-isturning-into-a-technology-industry. Acesso em: 23 jul. 2020.

WORLD COMPETITIVENESS REPORT. World Economic Forum 2020. Disponível em: https://www.weforum.org/strategic-intelligence/. Acesso em: 20 maio 2021. 